\title{
Challenges for medical education in Mexico in the time of COVID-19
}

\section{Retos para la educación médica en México en los tiempos del COVID-19}

\author{
Aldo Barajas-Ochoa, ${ }^{1 *}$ Jorge Santiago Andrade-Romo ${ }^{2}$ and Vicente O. Ramos-Santillán ${ }^{3}$ \\ ${ }^{1}$ Rutgers New Jersey Medical School, Department of Medicine, New Jersey; ${ }^{2}$ New York Eye and Ear Infirmary, Icahn School of Medicine, Mount \\ Sinai; ${ }^{3}$ Montefiore Medical Center, Albert Einstein College of Medicine, New York. United States of America
}

\section{Introduction}

By April 2, 2020, only 116 days after the description of the first case of SARS-CoV2 virus infection, which causes the COVID-19 disease, 1,014,673 cases and 50,030 deaths have been recorded in 181 countries. $^{1}$ In the United States, there have been 244,678 cases and 5,911 deaths recorded (in New York State alone, there are 93,053 cases and 2,538 deaths), while in Mexico, 1,378 cases and 37 deaths have been recorded. This number is expected to keep on increasing in both countries. The health system in Mexico, as well as in the rest of the world, will face an enormous problem in the months to come.

Mexico's medical education system has to adapt to the healthcare requirements generated by the pandemic. The undergraduate internship, the social service and the national system of medical residency are essential cycles in the training of doctors in Mexico. Undergraduate medical interns, house officers and residents represent an essential part of the physicians who carry out healthcare tasks and who will be exposed to patients with COVID-19. Between 2017, 2018 and 2019, 26,972 physicians (8480, 8821 and 9671, respectively) were accepted in the National System of Medical Residency in Mexico. ${ }^{2}$ Furthermore, according to the 2018-2019 higher education statistical yearbook of the National Association of Universities and Institutions of Higher Education, ${ }^{3}$ there were 139,272 undergraduate medical students, with 16,070 graduate physicians on training. Assuming that the number of graduates on training is similar to that of social service medical interns and undergraduate medical interns, there are approximately 32,000 undergraduate medical interns and house officers in Mexico. The addition of the above yields an approximate of 58,972 physicians in the medical education system clinical phase. However, health care burden and responsibilities at each stage are different, which requires defining the healthcare roles and recruitment strategies, and clarifying the level of risk that physicians on training will be exposed to.

The authors of this letter are doctors educated in the Mexican medical education system, and at this moment we are at the center of the pandemic caused by the SARS-CoV2 virus, New York City metropolitan area. We have experienced the lifestyle changes in the academic and healthcare areas, and we have observed the protection measures taken by institutions in the face of this emergency. We believe that some of our observations may be useful for the medical education system in Mexico.

\section{Guaranteeing personal protection supplies availability}

Regardless of the level of training, availability of supplies must be guaranteed in order to comply with personal protection measures. To assist COVID-19 patients, a regular mask or surgical mask is required (or N95 for aerosol-generating procedures such as endotracheal intubation), as well as eye protection license (http://creativecommons.org/licenses/by-nc-nd/4.0/).
} 
(goggles or face shields), gloves, and isolation gowns. The correct use of personal protective equipment decreases the probability of nosocomial infection, reduces the number of doctors who must be hospitalized or quarantined and the probability of transmission by them to the population. This way, the health system has more doctors available to treat patients, while reducing the number of infected individuals. However, in the early stages of the health emergency, lack of supplies and protocols has already been reported in places such as the National Institute of Respiratory Diseases; ${ }^{4}$ fellow residents from all over the country have expressed concerns for not having the supplies to comply with the personal protective measures at their hospitals, in addition to other resources. Mexico is not the only nation with this problem, which is also occurring in the United States and Italy, ${ }^{5}$ the two countries with more recorded cases of the disease to date, ${ }^{1}$ where several hospitals have been forced to depend on donations from external institutions or individuals.

\section{Defining the acceptable exposure risk according to the level of training}

The acceptable exposure risk of physicians on training should be defined. We celebrate the initiative taken by the General Directorate for Quality and Health Education (DGCES - Dirección General de Calidad y Educación en Salud) to protect trainee personnel. ${ }^{6}$ As of March 24, all undergraduate medical interns should not be present in areas of risk for COVID-19. Historically, undergraduate medical interns have the double condition of students ${ }^{7}$ and worker-employees. ${ }^{8,9}$ This DGCES measure denotes that the well-being of undergraduate medical interns trumps over their healthcare-related activities and highlights the role of the undergraduate medical intern as a student rather than as an employee. However, if health services are overwhelmed by the number of patients during the pandemic, consideration could be given to assigning undergraduate interns where they are needed.

The DCGES will not interrupt the healthcare-related activities of medical interns on social service and residents; in addition, it establishes that these doctors must receive the necessary equipment for their protection in the care of suspected and confirmed COVID-19 patients. The legal framework that defines the positions of medical interns on social service makes it difficult to determine the level of healthcare obligations they should be assigned during the pandemic. ${ }^{10,11}$ However, the work of these physicians is essential to the healthcare system at primary care level, since nearly one third of the primary care units of the public system are covered by them..$^{12}$ The DGCES establishes that resident physicians will continue with their clinical practice activities according to their academic program.

In addition, it is crucial to define the level of exposure of medical students who are on clinical rotations: which is the role of the student in the clinical setting during this pandemic? Unfortunately, unlike other situations that require an increase in medical attention, such as natural disasters in which the student can learn, in this pandemic, students can act as asymptomatic transmission agents, in addition to decreasing available personal protection supplies and COVID-19 tests in case they get sick.

This drove multiple medical schools in the United States to adopt immediate measures of social distancing and to restrict medical students access to healthcare areas, ${ }^{13}$ which has generated new challenges for medical education. Although prior to the pandemic some subjects of the curriculum were already taught online at United States medical schools, social distancing measures required for all basic science courses to migrate to this format. Social distancing significantly affected teaching in clinical fields by limiting patient-student interactions. Alternative strategies are still being developed, including the use of virtual cases and the use of telehealth, among others. ${ }^{13}$

In a timely manner, the DCGES suspended academic activities in clinical fields for students in health areas from March 23 on. Furthermore, the education of medical students in the first years of medical school will be affected by the interruption of face-to-face classes in educational institutions. The first steps required to mitigate COVID-19 transmission have affected the paradigm of health education in Mexico, and it will therefore be important to assess the consequences of these actions. Medical undergraduate education system may need to adjust to an online education system in the immediate future, which will require the effort of all members of the medical academic community to solve the new challenges.

\section{Adjusting the clinical activities of residents of different specialties according to health care burden}

Multiple healthcare systems in New York City implemented actions to prevent nosocomial transmission, 
including the cancellation of all elective surgical procedures, and numerous operating rooms have been transformed into intensive care units in order to increase mechanical ventilation devices availability. This led to a decrease in health care burden for surgical specialty medical residents, who remained in a "reserve status" and joined the pandemic response teams. Since surgical specialty residents sometimes lack sufficient experience in the management of patients with complex, non-surgical diseases, it was essential to create multidisciplinary teams, in which personnel with more experience in the management of medical diseases serve as group leaders. It is possible that his strategy may be necessary in Mexico. On the other hand, most patients with COVID-19 are admitted to internal medicine or intensive care departments, where health care burden is overwhelming.

Furthermore, various hospitals have created protocols or clinical practice guidelines for the management of patients with COVID-19, which are based on evidence and on available supplies and personnel at the institution. These protocols are continuously updated according to new findings on the disease. Following a consistent, evidence-based treatment allows health personnel on training to learn to manage COVID-19. The creation of these protocols by hospitals in Mexico will standardize the treatment of patients with COVID-19 at each institution.

\section{Establishing measures to preserve mental health}

Healthcare personnel participating in the pandemic response team will be exposed to high levels of stress. The sources of stress include witnessing scenes of human suffering, the health risk the personnel is exposed to, decision-making in matters of life and death, intense health care burdens, lack of resources and being separated from the family. The institutions those who wrote this letter work for have established different strategies for the management of stress in health workers; it is important for these strategies to be planned for trainee physicians who participate in the pandemic.

\section{Adapting the recruitment of new residents to social distancing measures}

Finally, although the recruitment of graduate and undergraduate medical interns in their health care positions may not be affected, this is not the case with resident physicians. The National Exam for Medical Residency Applicants (ENARM - Examen Nacional para Aspirantes a Residencias Médicas) has historically required physicians to travel to the sites where the exam is applied, which generates large congregations. The $44^{\text {th }}$ ENARM will be held from September 25 to 30, 2020;14 however, it has been estimated that social distancing will have to be active until vaccines or pharmacological strategies are created to treat the disease, i.e., perhaps more than 18 months. ${ }^{15}$ What are the measures to be taken to adapt the selection of resident physicians?

\section{Conclusions}

Without a doubt, Mexican society will have to make difficult decisions when facing the pandemic generated by the SARS-CoV2 virus. The health system must be prepared to provide care to patients who require medical attention when contracting COVID-19. The medical education system in Mexico will have to be adapted to overcome as best as possible the challenges generated by the pandemic, as well as to define the risk of acceptable exposure according to the level of training, ensure that the supplies for personal protection are available, adjust the health care burden according to patient flow, protect the mental health of trainee physicians, and plan the recruitment and education of the new physicians who will join the medical education system. Undoubtedly, this is not an exhaustive list and there will be many other situations that should be considered in the future, but we hope that these reflections serve as a catalyst for future discussions for the planning of medical education in Mexico in times of COVID-19.

\section{Ethical disclosure}

Protection of people and animals. The authors declare that no experiments were performed on humans or animals for this study.

Confidentiality of data. The authors declare that no patient data appear in this article.

\section{References}

1. Johns Hopkins University/CoronavirusResource Center [website]. World Map. COVID-19 Dashboard by the Center for Systems Science and Engineering (CSSE) at Johns Hopkins University (JHU). United States: Johns Hopkins University; 2020.

2. Comisión Interinstitucional para la Formación de Recursos Humanos para la Salud [website]. Reportes académicos. Médicos inscritos, sustentantes, seleccionados y resultados por escuela o facultad de medicina. México: CIFRHS. Updated Nov 13, 2019. 
3. Anuario estadístico de educación superior 2018-2019. México: Asociación Nacional de Universidades e Instituciones de Educación Superior; 2020.

4. Miranda P. Personal del INER protesta por falta de protocolos ante Covid-19. El Universal [website]. March 17, 2020.

5. Ranney ML, Griffeth V, Jha AK. Critical supply shortages-The need fo ventilators and personal protective equipment during the Covid-19 pandemic. N Engl J Med. 2020.

6. Dirección General de Calidad y Educación en Salud [website]. Comunicado. Para personal en formación. México: Dirección General de Calidad y Educación en Salud. [Published on March 23, 2020].

7. Norma Oficial Mexicana NOM-234-SSA1-2003, utilización de campos clínicos para ciclos clínicos e internado de pregrado. México: Diario Oficial de la Federación 2005 Jan 06.

8. Frenk, J. La atención médica, la enseñanza de la medicina y el mercado de trabajo para los médicos: el internado en México. Educ Med Salud. 1984;18:329-343.
9. Ríos-Cortázar V, Gasca-García A, Urbina-García R, Flores-Echavarría R, Lloret-Rivas A. Nuevos modelos educativos en el internado médico de pregrado. La participación de la Universidad. Reencuentro. 2005;42:1-16

10. Mazón-Ramírez JJ. El marco jurídico del servicio social. Gac Med Mex. 2012:148:284-291.

11. Illescas-Martínez I, Luis-Reyes A. Reglamentación del servicio social de medicina en México, a más de 80 años de su implantación. Salud y Administración. 2019;6:27-37.

12. Nigenda G. Servicio social en medicina en México. Una reforma urgente y posible. Gac Med Mex 2013;55:519-527.

13. Rose S. Medical student education in the time of COVID-19. JAMA. 2020

14. Comisión Interinstitucional para la Formación de Recursos Humanos para la Salud [website]. Convocatoria. XLIV Examen Nacional para Aspirantes a Residencias Médicas 2020. México: CIFRHS; 2020.

5. Imperial College COVID-19 Response Team. Impact of non-pharmaceutical interventions (NPIs) to reduce COVID19 mortality and healthcare demand. Reino Unido: Imperial College London; 2020. 